\title{
La modesta protección de los consumidores en la Carta de los Derechos Fundamentales de la Unión Europea y su potencial'
}

\author{
Dr. Santiago Larrazabal Basáñez \\ Profesor de Derecho Constitucional y Director del Departamento de Derecho Público \\ Universidad de Deusto
}

Recibido: $\quad$ 19.05.11

Aceptado: 28.06.11

Sumario: I. Introducción. II. Un deseo convertido en realidad: la Carta de los Derechos Fundamentales de la Unión Europea ya es jurídicamente vinculante. III. La «modesta» configuración de la protección de los consumidores en la Carta. IV. El «potencial» de la protección de los consumidores en el derecho derivado y en la jurisprudencia del Tribunal. V. Conclusión. VI. Bibliografía. VII. Jurisprudencia seleccionada del Tribunal de Justicia en materia de protección al consumidor. VIII. Jurisprudencia seleccionada del Tribunal de Justicia en relación con la aplicación de la Carta. IX. Conclusiones de los Abogados Generales citadas en el texto.

Resumen: El presente texto estudia las posibilidades que ofrece el artículo 8 de la Carta de los Derechos Fundamentales de la Unión Europea en materia de protección de los consumidores, analizándolas desde la promulgación de la Carta en el año 2000 hasta la entrada en vigor del Tratado de Lisboa, que ha reconocido a la Carta el mismo valor jurídico que los Tratados, y también respecto al nuevo período que se abre tras el Tratado de Lisboa, y trata de demostrar cómo, a pesar de lo modesto de la regulación de la protección de los consumidores en la Carta, al ser definida como un principio y no como un derecho, este artículo tiene mucho potencial de desarrollo, tanto en los actos legislativos y ejecutivos de la Unión, como en caso de los Estados cuando apliquen el derecho de ésta y, especialmente, en la jurisprudencia del Tribunal de Justicia de la Unión Europea.

1 Este artículo se inspira, aunque reformulándola y completándola, en la ponencia que con el título «La protección de los consumidores en la Carta de los Derechos Fundamentales de la Unión Europea», desarrollé en la "Jornada sobre Derecho, cooperativismo y defensa de los consumidores» que, organizada conjuntamente por la Asociación Internacional de Derecho Cooperativo y la Academia Vasca de Derecho, tuvo lugar en Bilbao, en el Salón de Actos del Ilustre Colegio de Abogados del Señorío de Bizkaia, el lunes 13 de diciembre de 2010. El texto original de mi ponencia aparece publicado en la Revista denominada, Jado. Boletín de la Academia Vasca de Derecho. 
Palabras clave: Unión Europea, Carta de los Derechos Fundamentales, Protección de los consumidores.

Abstract: This paper studies the possibilities that article 38 of the Charter of Fundamental Rights of the European Union offers for consumer protection. Analysis begins with enactment of the Charter in 2000 to the time that the Lisbon Treaty went into effect and acknowledged that the Charter had the same legal value as the treaties. The study then goes on to focus on the new period following the Lisbon Treaty and aims to demonstrate that article 38 has great potential for development through EU legislation and executive orders in spite of the modest regulation of consumer protection in the Charter. This is due to the definition of this protection as a principle and not a right. Development is also expected as the member states apply EU law and especially as jurisprudence is handed down by the European Court of Justice.

Key words: European Union, Charter of Fundamental Rights, consumer protection. 


\section{Introducción}

Hace algo más de tres años, el 13 de diciembre de 2007, tenía lugar la firma del Tratado de Lisboa, que entró en vigor en diciembre de 2009 tras un largo y tortuoso proceso de ratificación por parte de los Estados miembros de la Unión Europea. Con este motivo, me gustaría analizar, siquiera brevemente, uno de los cambios más importantes que la entrada en vigor del Tratado de Lisboa ha supuesto en lo que se refiere al carácter vinculante de la Carta de los Derechos Fundamentales de la Unión Europea. Y en el marco de la Carta, quisiera reflexionar acerca de los denominados «derechos sociales», que aparecen incluidos en su Título IV bajo el epígrafe "Solidaridad». En realidad, se trata de continuar con una reflexión que comencé el año pasado con motivo del Simposio que la Asociación Internacional de Derecho Cooperativo, la Academia Vasca de Derecho y el Instituto de Estudios Vascos de la Universidad de Deusto dedicaron al tema "Crisis e intercooperación» ${ }^{2}$. En él, tuve ocasión de referirme al siempre difícil equilibrio entre libertades económicas y derechos sociales en el proceso de construcción europea. ${ }^{3}$

Retomando la reflexión acerca de los derechos sociales en la Unión Europea y en el ámbito del tema "Cooperativismo y Consumo», que estableció la Asamblea de la Asociación Internacional de Derecho Cooperativo como línea de investigación para el año 2010, he seleccionado precisamente la protección del consumidor, recogida en el artículo 38 de la Carta, dentro del ya mencionado epígrafe "Solidaridad», para continuar mi reflexión sobre la protección de los derechos sociales y de los principios recogidos en la misma. Para ello, y con el permiso del lector, utilizaré un símil futbolístico, describiendo la protección de los derechos sociales, la construcción de una auténtica Europa social y, en definitiva, la culminación de un proceso de integración europea que vaya más allá de un mercado único y de una unión monetaria, como una larga y disputada liga, con distintas eliminatorias a superar, hasta la consecución del objetivo final: una auténtica integración europea en

2 Este Simposio, bajo el título «Crisis e intercooperación», corresponde al VIII Simposio sobre la Cultura Económica Vasca y fue organizado conjuntamente por el Instituto de Estudios Vascos de la Universidad de Deusto, la Asociación Internacional de Derecho Cooperativo y la Academia Vasca de Derecho. Tuvo lugar, en Bilbao, el 14 de diciembre de 2009 en la sede del Ilustre Colegio de Abogados del Señorío de Bizkaia.

3 Mi reflexión dio lugar al artículo «La Constitución económica de la Unión Europea y el difícil equilibrio entre las libertades económicas y los derechos sociales», Boletín de la Asociación Internacional de Derecho Cooperativo, n. 44 (2010), pp. 221-250. 
todos los ámbitos. Me he tomado la libertad de comparar este largo y tortuoso proceso con la participación de un equipo de fútbol en la Liga de fútbol europea organizada por la UEFA, la célebre «Europe Champions League». En esta «liga de la integración europea», como en la futbolística, hay que disputar muchos partidos. A veces se gana y otras se pierde, pero siempre hay que hacer grandes esfuerzos y sacrificios para lograr clasificarse para las siguientes eliminatorias, hasta llegar a disputar la final y, naturalmente, intentar ganarla.

Volviendo al tema de la integración europea, esta «liga» se disputa entre euroconvencidos y euroescépticos, y existen distintos niveles en el proceso de avance hacia una integración europea plena y existen, como en el fútbol, varias «divisiones» (primera, segunda, tercera, etc.). Así, las libertades económicas y el mercado único, que han conocido un gran avance a lo largo de todos estos años, estarían situados en la primera división. Por el contrario, la Unión monetaria va más despacio, y a día de hoy, sólo diecisiete de los veintisiete países miembros de la Unión, forman parte de la moneda única. Por su parte, en materia de derechos, los derechos civiles y políticos avanzan rápido, pero los derechos económicos y sociales y la Europa Social van mucho más despacio ${ }^{4}$, al igual que ocurre con los denominados «derechos de tercera generación». Y, aún más, en el ámbito de la Carta de los Derechos Fundamentales aún existe una categoría más modesta que la de los derechos, la de los principios, entre los que se encuentra, precisamente, el de la protección de los consumidores, regulado en el art. 38 de la misma y al que me voy a referir en este artículo.

Pero regresemos por un momento al argot futbolístico: nuestro equipo (el que defiende los colores del principio de protección del consumidor) es, en teoría, uno de los equipos más modestos de los que compiten en la «Champions League», porque es recogido en la Carta

${ }^{4}$ Cfr. Ashiagbor, D.: «Economic and social rights in the European Charter of Fundamental Rights», European Human Rights Law Review, n. ${ }^{\circ}$ (2004), pp. 62-72; Corriente Córdoba, J.A.: "La protección de los derechos económicos, sociales y culturales en la Carta de los Derechos Fundamentales de la Unión Europea», Anuario de Derecho Europeo, n. 2 (2002), pp. 117-135; Gil y Gil, J.L. / Ushakova, T.: «Los derechos sociales en la Carta de los Derechos Fundamentales de la Unión Europea», Relaciones laborales: Revista crítica de teoría y práctica, n. ${ }^{\circ} 2$ (2002), pp. 1319-1344; Hervey, T. / Kenner, $J .:$ Economic and social rights under the EU charter of fundamental rights: a legal perspective, Oxford: Hart, 2006; Pérez Pérez, G.: "La problemática de los derechos sociales en la Carta de los Derechos Fundamentales de la Unión Europea», Cuestiones constitucionales: Revista mexicana de Derecho constitucional, n. ${ }^{\circ} 18$ (2008); Tur Ausina, R.: "Luces y sombras de los derechos sociales en la Carta de los Derechos Fundamentales de la Unión Europea», Revista Europea de Derechos Fundamentales, n. 13 (2009), pp. 323-349. ISSN: 1134 - 993X, Núm. 45/2011, Bilbao, págs. 161-189 
sólo como un principio, ni siquiera como un derecho, con las consecuencias jurídicas que, como veremos, ello tiene en cuanto a la posibilidad de ser alegado ante los órganos jurisdiccionales. Ahora bien, como ocurre a veces con los equipos de fútbol modestos, la protección de los consumidores nos ha dado, nos sigue dando y creo que nos seguirá dando en el futuro numerosas satisfacciones pues, a pesar de la débil posición que ocupa en la Carta, a través de la normativa y de la jurisprudencia europeas, su nivel de protección va adquiriendo cada vez más importancia. Es decir, a pesar de su «modesta» regulación jurídica en la Carta, creo que —utilizando de nuevo el argot futbolístico-, tiene mucho «potencial».

\section{Un deseo convertido en realidad: la Carta de los Derechos Fundamentales de la Unión Europea ya es jurídicamente vinculante}

Esta larga y a menudo tortuosa historia de la construcción europea, como cualquier liga deportiva, incluye varios partidos a disputar entre quienes quieren profundizar mucho más en la integración y quienes no quieren ir más allá de donde estamos, e incluso en algunos casos, creen que se ha ido demasiado lejos y que habría que retroceder un poco o — los más escépticos - incluso más que un poco. Y en esta eliminatoria, los partidarios de una mayor integración (entre los que me cuento), van avanzando poco a poco, persuadidos de su victoria final aun siendo plenamente conscientes de que la cosa no va a ser nada fácil.

Siguiendo con el símil futbolístico, una de las series de la liga de integración europea ha sido la relativa a la aprobación de una Carta de Derechos Fundamentales para la Unión. Y el primer partido de la fase de clasificación, lo ganamos simbólicamente los «euroconvencidos» y digo simbólicamente porque el 7 de diciembre de 2000 en Niza fue proclamada la Carta de Derechos Fundamentales, muy solemnemente eso sí, pero sin carácter vinculante, por lo que se convirtió jurídicamente en un ejemplo de lo que ahora denominamos "soft law», que permitió su utilización como ayuda para la interpretación del derecho comunitario e incluso del derecho interno de los países miembros ${ }^{5}$,

5 Piénsese, por ejemplo, en el caso español, la recepción que puede tener en la interpretación y aplicación del propio derecho español, a través de lo previsto en el art. 10.2 de la Constitución española, que establece que «las normas relativas a los derechos fundamentales y a las libertades que la Constitución reconoce, se interpreta- 
pero no permitió ir mucho más allá puesto que, evidentemente, en esta fase, la Carta no formaba parte del ordenamiento jurídico comunitario y el Tribunal de Justicia no era competente para interpretarla6. Ahora bien, como dijo la Abogada General Trstenjak en sus Conclusiones Generales el 7 de mayo de 2009 en el asunto Martín Martín?: «... en lo que respecta a las disposiciones de la Carta, querría señalar que éstas no forman parte del ordenamiento comunitario, de modo que el Tribu-

rán de conformidad con la Declaración Universal de Derechos Humanos y los tratados y acuerdos internacionales sobre las mismas materias ratificados por España» y de la interpretación que de esta disposición ha hecho el Tribunal Constitucional español en reiterada jurisprudencia (por ejemplo, en sus Sentencias de 23 de noviembre de 1981; 78/1982, de 20 de diciembre; 64/1991, de 22 de mayo; 254/1993, de 20 de julio; 197/2006, de 3 de julio, y 236/2007, de 7 de noviembre). Y esta recepción no sólo se refiere al Convenio Europeo de Derechos Humanos sino también a la Carta de Derechos Fundamentales de la Unión Europea.

Sobre este asunto, puede consultarse: Andrés Sáenz de Santamaría, P.: «La Carta de los Derechos Fundamentales de la Unión Europea en la práctica española», Revista de Derecho de la Unión Europea, n. 15 (2008), pp. 233-255; Arzoz Santisteban, X.: «La relevancia del derecho de la Unión Europea para la interpretación de los derechos fundamentales constitucionales», Revista Española de Derecho Constitucional, n. ${ }^{\circ} 74$ (2005), pp. 63-110; Aziz, M.: The impact of European rights on national legal cultures, Oxford: Hart, 2004; Rodríguez García, L.F.: «La recepción de la Carta de Derechos Fundamentales de la Unión Europea en la legislación y la jurisprudencia españolas antes de su vigencia», en García Roca, F.J. (coord.): Treinta años de Constitución, Valencia: Tirant lo Blanch, 2010, pp. 561-584; Tizzano, A.: «La protection des droits fondamentaux en Europe. La Cour de justice et les jurisdictions constitutionnelles nationales», Revue du droit de l'Union Européenne, n. ${ }^{\circ} 1$ (2006), pp. 9-21.

6 Sobre este particular, pueden consultarse: Alonso García, R.: «La Carta de los derechos fundamentales de la Unión Europea», Gaceta Jurídica de la CE, n. ${ }^{\circ} 209$ (2000), pp. 3-17; Alston, P. / Bustelo, M.R. / Heenan, J. (dirs.): L'Union européenne et les droits de l'homme, Bruxelles: Bruylant, 2001; Bogdandy, A. von: «The European Union as a human rights organization: human rights and the core of the European Union», Common Market Law Review, vol. 37, n. ${ }^{\circ} 6$ (2000), pp. 1307-1338; Dutheil de la Rochere, J.: "La Chartre des droits fondamentaux de I'Union Européenne: quelle valeur ajoutée, quel avenir?», Revue du Marché Commun et de l'Union Européenne, n. 443 (2000), pp. 674-680; Fernández Tomás, A.: «La Carta de derechos fundamentales de la Unión Europea: un nuevo hito en el camino de la protección», Gaceta Jurídica de la Unión Europea y de la competencia, n. ${ }^{\circ} 214$ (2001), pp. 15-30; Fernández Tomás, A.: La Carta de los derechos fundamentales de la Unión Europea, Valencia: Tirant lo Blanch, 2002; Herrero de la Fuente, A. (ed.): La Carta de Derechos Fundamentales de la Unión Europea. Una perspectiva pluridisciplinar, Zamora: Fundación Rei Alfonso Henriques, 2003; Pi Llorens, M.: La Carta de los Derechos Fundamentales de la Unión Europea, BarceIona: Universitat, 2001; Rodríguez Bereijo, A.: «La Carta de los derechos fundamentales de la Unión Europea», Noticias de la Unión Europea, n. 192 (2001), pp. 9-20; Vitorino, A.: «La Charte des droits fondamentaux de I'Union européenne», Revue du Droit de I'Union Européenne, n. ${ }^{\circ} 1$ (2000), pp. 27-64.

7 Sentencia de 17 de diciembre de 2009, Martín Martín, C-227/08, Rec. p. I-0000. Apartado 44 de sus Conclusiones. ISSN: 1134 - 993X, Núm. 45/2011, Bilbao, págs. 161-189 
nal de Justicia no es competente para interpretarlas. No obstante, es cierto que a menudo los Abogados Generales ${ }^{8}$ hacen referencia a dicho documento en las argumentaciones de sus conclusiones y que el Tribunal de Justicia también ha citado la Carta en su jurisprudencia» ${ }^{9}$

El segundo partido de esta fase lo ganaron, sin embargo, los euroescépticos: el 29 de octubre de 2004 se aprobó en Roma el «Tratado por el que se establece una Constitución para Europa», que incorporaba la Carta de Derechos Fundamentales como Parte II del mismo ${ }^{10}$. Como es de sobra conocido, tras los fracasos en los referendos de ratificación del mismo en Francia y Holanda y la negativa de algunos Estados para continuar con el proceso de ratificación, el denominado «Tratado Constitucional» encalló y quedó en nada.

El tercer partido de esta fase terminó con la aprobación del Tratado de Lisboa, el 13 de diciembre de 2007, hace exactamente tres años, y con la entrada en vigor del mismo hace un año. En este partido, los «euroconvencidos» nos resarcimos un poco de la amarga experiencia

8 En efecto, la Abogada General cita las conclusiones presentadas por el Abogado General Poiares Maduro el 9 de septiembre de 2008 en el asunto Elgafaji (Sentencia de 17 de febrero de 2009, C-465/07, Rec. p. I-00921), apartados 21 y 23; por la propia Abogada General Trstenjak el 11 de septiembre de 2008 en el asunto Gorostiaga Atxalandabaso/Parlamento (Sentencia de 19 de febrero de 2009, C-308/07 O, Rec. p. I-01059), apartados 56, 91 y 92; por el Abogado General Mengozzi el 21 de enero de 2009 en el asunto Mono Car Styling ((Sentencia de 16 de julio de 2009, C-12/08, Rec. p. I-06653), apartados 49, 83, 95 y 97 y las conclusiones de la Abogada General Kokott el 22 de enero de 2009 en el asunto Mellor (Sentencia de 30 de abril de 2009, C-75/08, Rec. p. I-03799), apartados 24, 25 y 33.

9 Por ejemplo, en la Sentencia de 13 de marzo de 2007, Unibet, C-432/05, Rec. p. I-2271, apartado 37, si bien anteriormente se había negado a interpretar la Carta a pesar de que, en una cuestión prejudicial, el Tribunal de origen le había pedido que interpretase el sentido y alcance de algunos artículos de la misma en relación con el caso concreto planteado (Auto de 6 de octubre de 2005, Vajnai, C-328/04, Rec. p. I-8577, apartado 13).

10 Cfr. Arnull, A.: «From Charter to Constitution and beyond: fundamental rights in the new European Union», Public Law, 2003 (winter), pp. 774-793; Canedo Arrillaga, J.R. / Gordillo Pérez, L.I.: "Los derechos fundamentales en la Unión Europea a la espera de Lisboa», Cuadernos Europeos de Deusto, n. 39 (2008), pp. 27-59; Díaz Crego, M.: «Los derechos fundamentales en la Unión Europea: de la carta a la Constitución», Revista Española de Derecho Constitucional, n. 74 (2005), pp. 139-175; Douglas-Scott, S.: "The Charter of Fundamental Rights as a constitutional document», European Human Law Review, n. ${ }^{\circ}$ (2004), pp. 37-50; Ehlers, D.: European fundamental rights and freedoms, Berlin: De Gruyter, 2007; Mayer, F.C.: "La Charte européenne des droits fondamentaux et la Constitution européenne», Revue Trimestrielle de Droit Européen, vol. 39 (2003-2), pp. 176 y ss.; Ruiz Miguel, C.: Estudios sobre la Carta de los derechos fundamentales de la Unión Europea, Santiago de Compostela: Universidade de Santiago de Compostela, 2004. 
del fracaso de la denominada Constitución europea y, en lo que se refiere a la Carta, conseguimos que el Tratado modificase el art. 6 del Tratado de la Unión Europea y que, más en concreto, el nuevo art. 6.1 estableciese que « la Unión Europea reconoce los derechos, libertades y principios enunciados en la Carta de los Derechos Fundamentales de la Unión Europea de 7 de diciembre de 2000, tal y como fue adoptada el 12 de diciembre de 2007 en Estrasburgo, la cual tendrá el mismo valor jurídico que los Tratados». El texto de la Carta, que fue proclamada otra vez de modo enfático un día antes de la firma del Tratado de Lisboa, introduce ligeras modificaciones al texto original de la Carta y es el que se encuentra actualmente en vigor ya con carácter vinculante. ${ }^{11}$

11 Sobre este tema, pueden consultarse las siguientes obras: Alonso García, R. / Sarmiento, D.: La Carta de los Derechos Fundamentales de la Unión Europea. Explicaciones, concordancias, jurisprudencia, Cizur Menor: Thomson-Civitas, 2006; Díaz Crego, M.: Protección de los derechos fundamentales en la Unión Europea y en los Estados miembros, Madrid: Reus, 2009; Ehlers, D.: European fundamental rights and freedoms, Berlin: De Gruyter, 2007; García Roca, J. / Aguilera Vaqués, M.: Integración europea a través de derechos fundamentales: de un sistema binario a otro integrado, Madrid: Centro de Estudios Políticos y Constitucionales, 2009; Krisch, N.: «The open architecture of European human rights law», The Modern Law Review, vol. 71, n. 2 (2008), pp. 183216; Liñán Nogueras, D.J. / Martín Rodríguez, P.J.: «Reflexiones sobre los derechos fundamentales de la Unión Europea a la luz del Tratado de Lisboa». En Derecho internacional y comunitario ante los retos de nuestro tiempo. Homenaje a la Profesora Victoria Abellán Honrubia, Madrid: Marcial Pons, 2009, pp. 1053 y ss.; Mangas Martín, A. (dir.): Carta de los derechos fundamentales de la Unión Europea: comentario artículo por artículo, Bilbao: Fundación BBVA, 2008; Martín y Pérez de Nanclares, J.: «The protection of human rights in the European Union». En Gómez Isa, F. / De Feyter, K. (dirs.): International Human Rights Law in a Global Context, Bilbao: Universidad de Deusto, 2009, pp. 777 y ss.; Monereo Pérez, J.L.: La protección de los derechos fundamentales: el modelo europeo, Albacete: Bomarzo, 2009; Murray, J.L.: «Fundamental rights in the European Community legal order», Fordham International Law Journal, vol. 32, n. 2 (2009), pp. 531-550; Ortiz Herrera, S.: Los Derechos Fundamentales en los Tratados Europeos. Evolución y situación actual, Madrid: CEU Ediciones, 2010; Palacio González, J.: «La protección de los derechos fundamentales por el Tribunal de Justicia de la UE: alcance y consecuencias de la futura adhesión de la UE al Convenio Europeo», Cuadernos Europeos de Deusto, n. 40 (2009), pp. 161-179; Pardo Getino, L.A.: "Los Derechos Humanos en el marco de la última reforma de la Unión Europea», Revista General de Derecho Europeo, n. 21 (2010); Parejo Navajas, T.: «La Carta de los derechos fundamentales de la Unión Europea», Derechos y libertades: Revista del Instituto Bartolomé de las Casas, año 14, n. 22 (2010), pp. 205-239; Picod, F.: «Art. II-84», en Bourgorge-Larsen, L. / Levade, A. / Picod, F. (dirs.): Traité Établissant une Constitution pour l'Europe. Partie II: La Charte des droits fondamentaux de l'Union. Commentaire article per article, Bruselas: Bruylant, 2005, pp. 494-502; Rideau, J.: Les droits fondamentaux dans I'Union Européenne. Dans le sillage de la Constitution européenne, Bruxelles: Bruylant, 2010; Skouris, W. I Favreau, B.: Le charte des droits fondamentaux de I'Union Européenne après le traité de Lisbonne, Bruxelles: Bruylant, 2010. ISSN: 1134 - 993X, Núm. 45/2011, Bilbao, págs. 161-189 
Aunque este partido lo ganásemos esta vez los «euroconvencidos», la victoria no fue completa: ciertamente, el partido se ganó, porque la Unión Europea cuenta ahora con un elenco de principios, derechos y libertades que tiene el mismo valor jurídico que los Tratados y por tanto es jurídicamente vinculante, es decir, ya no es "soft law». Pero hay que hacer algunas precisiones: hubo dos jugadores del partido que se autoexcluyeron totalmente del mismo y un tercero que también hizo algo similar aunque de forma menos tajante: me refiero al Protocolo n. ${ }^{\circ} 4$ al Tratado de Lisboa, que excluye de la aplicación de la Carta al Reino Unido y a Polonia'2, y en cierto sentido, a la República Checa.

Siguiendo con el símil futbolístico, y como ocurre en esos programas «postpartido» de radio y televisión, en los artículos de prensa o incluso en los vivos debates que tienen lugar en las redes sociales, voy a intentar en este artículo analizar brevemente uno de los aspectos de este tercer partido, haciendo una ficha rápida del mismo: en mi opinión, se trata de una victoria, porque la Carta tiene carácter vinculante y el mismo valor jurídico que los Tratados constitutivos de la Unión Europea. Como dice su Preámbulo, la Carta reafirma los derechos que emanan, en particular, de las tradiciones constitucionales y las obligaciones internacionales comunes a los Estados miembros, del Convenio Europeo para la Protección de los Derechos Humanos y de las Libertades Fundamentales, las Cartas Sociales adoptadas por la Unión y por el Consejo de Europa, así como de la jurisprudencia del Tribunal de Justicia de la Unión Europea y del Tribunal Europeo de Derechos Humanos. Por su parte, el art. 51 de la Carta, marca los límites del campo de juego, pues establece que las disposiciones de la Carta están dirigidas a las instituciones, órganos y organismos de la Unión, dentro del respeto al principio de subsidiariedad, así como a los Estados miembros, pero en este último caso únicamente cuando apliquen el Derecho de la Unión. Ahora bien, tal y como dicen, tanto el párrafo segundo del art. 6.1. del Tratado de la Unión Europea como la Declaración relativa a la Carta (Declaración n. ${ }^{\circ} 1$ anexa al Tratado de Lisboa), ésta no amplía

12 V. Protocolo sobre la aplicación de la Carta de los Derechos Fundamentales de la Unión Europea a Polonia y al Reino Unido (Protocolo n. ${ }^{\circ} 30$ del Tratado de Lisboa). En relación con Polonia, debe tenerse en cuenta la Declaración n. ${ }^{\circ} 62$ (anexa al Tratado de Lisboa) de la República de Polonia relativa al Protocolo sobre la aplicación de la Carta de los Derechos Fundamentales de la Unión Europea a Polonia y al Reino Unido, además de la Declaración n. ${ }^{\circ} 61$ (anexa al Tratado de Lisboa) relativa a la Carta de los Derechos Fundamentales de la Unión Europea. En el caso de la República Checa, hay que tener en cuenta la Declaración n. ${ }^{\circ} 53$ (anexa al Tratado de Lisboa) de la República Checa relativa a la Carta de los Derechos Fundamentales de la Unión Europea. 
el ámbito de aplicación del Derecho de la Unión más allá de las propias competencias de la Unión, ni crea ninguna nueva competencia ni ningún nuevo cometido para la Unión y tampoco modifica las competencias y cometidos definidos por los Tratados. ${ }^{13}$

En cuanto a su interpretación, el art. 6.1 del Tratado de la Unión Europea establece en su párrafo final que los derechos, libertades y principios de la Carta se interpretarán con arreglo a las disposiciones generales del Título VII de la propia Carta y teniendo en cuenta las «explicaciones» (la denominada Guía) a que se hace referencia en la Carta, que indican las fuentes de dichas disposiciones. Estas "explicaciones» acompañan a cada artículo y fueron elaboradas por el Praesidium de la Convención que redactó la Carta y actualizadas bajo la responsabilidad del Praesidium de la Convención Europea. Estas explicaciones se nutren de la propia jurisprudencia del Tribunal de Justicia, del Tribunal Europeo de Derechos Humanos y de las tradiciones constitucionales comunes de los países miembros de la Unión.

Finalmente, habrá que esperar para ver con un poco más de perspectiva cuál es la aplicación concreta que hace el Tribunal de Justicia de los distintos artículos de la Carta, porque ésta ya está en vigor y forma parte del derecho originario de la Unión Europea, pero desde hace sólo un año, desde diciembre de 2009. El Tribunal ya ha empezado a interpretar el derecho de la Unión, dentro de los límites de las competencias atribuidas a ésta, a la luz de la Carta, interpretando sólo el derecho de la Unión y no el derecho nacional. Y en el caso de algunos derechos de la Carta, que se corresponden con los derechos garantizados por el Convenio Europeo para la Protección de los Derechos Humanos y de las Libertades Fundamentales y que, según lo establecido en el art. 52.3 de la Carta, serán interpretados de tal manera que su sentido y alcance serán iguales a los que les confiere dicho Convenio, el Tribunal ha aplicado miméticamente el Convenio Europeo y la jurisprudencia del Tribunal Europeo de Derechos Humanos. Así ha ocurrido, por ejemplo, en el caso del art. 7 de la Carta (respeto de la vida privada y familiar), cuando el Tribunal se ha remitido automáticamente al art. 8.1 del Convenio Europeo, tal y como lo interpreta la jurisprudencia del Tribunal Europeo de Derechos Humanos ${ }^{14}$.

13 Vid. Linde Paniagua, E.: «El ámbito de aplicación: el talón de Aquiles de la Carta de los derechos fundamentales de la Unión Europea», Revista de Derecho de la Unión Europea, n. 15 (2008), pp. 27-44; Mangas Martín, A. / Liñán Nogueras, D.J.: Instituciones y Derecho de la Unión Europea, Madrid: Tecnos, 6. ${ }^{a}$ ed., 2010, pp. 125-127.

14 Sentencia del Tribunal de Justicia de 5 de octubre de 2010, McB, C-400/10 PPU, Rec. p. I-0000, apartados 50-53. 
Ahora bien, también hay que decir que el Tribunal ya había aludido a este artículo de la Carta, y al artículo 24 de la misma (derechos del niño) aun antes de que ésta entrase en vigor en 2009. Y así, en el apartado 48 de la Sentencia del caso Varec ${ }^{15}$, llegó a decir que «...Varec alegó ante el Conseil d'État que el derecho a un proceso justo implica que se garantice el carácter contradictorio de todo procedimiento judicial, que el principio de contradicción constituye un principio general del Derecho, que se basa en el artículo 6 del CEDH, y que este principio implica el derecho de las partes procesales de obtener comunicación de todo escrito o alegación presentados al juez para influir en su decisión, y de discutirlos. Sobre este particular, procede subrayar que el artículo 6, apartado 1, del CEDH establece, concretamente, que "toda persona tiene derecho a que su causa sea oída equitativa, públicamente y dentro de un plazo razonable, por un Tribunal independiente e imparcial [...]".

Según reiterada jurisprudencia del Tribunal Europeo de Derechos Humanos, el carácter contradictorio de un procedimiento constituye uno de los elementos que permiten apreciar su carácter justo, pero puede ser ponderado con otros derechos e intereses. Por regla general, el principio de contradicción implica el derecho de las partes procesales de obtener comunicación de las pruebas y alegaciones presentadas ante el juez y de discutirlas. Sin embargo, en algunos casos puede resultar necesario no comunicar determinada información a las partes para preservar los derechos fundamentales de un tercero o para proteger un interés público importante (véase TEDH, sentencias Rowe y Davis c. Reino Unido, de 16 de febrero de 2000, Recueil des arrêts et décisions 2000-II, \& 61, y V. c. Finlandia, de 24 de abril de 2007, aún no publicada en el Recueil des arrêts et décisions, § 75). Entre los derechos fundamentales que pueden ser así protegidos figura el derecho al respeto de la intimidad, que está recogido en el artículo 8 del CEDH y que tiene su origen en las tradiciones constitucionales comunes de los Estados miembros y se reafirma en el artículo 7 de la Carta de los Derechos Fundamentales de la Unión Europea, proclamada en Niza el 7 de diciembre de 2000...»

Y de forma similar, al estudiar el recurso de anulación del Parlamento Europeo contra los artículos 4, párrafos $1 .^{\circ}$ y $6 .^{\circ}$ y contra el artículo 8 de la Directiva 2003/86/CE del Consejo, de 22 de septiembre de 2003, sobre el derecho a la reagrupación familiar ${ }^{16}$, en el caso Parla-

15 Sentencia de 14 de febrero de 2008, Varec, C-450/06, Rec. p. I-00581, apartados $45-48$ y $60-62$.

16 Directiva 2003/86/CE del Consejo, de 22 de septiembre de 2003, sobre el derecho a la reagrupación familiar DO L 251, p. 12. 
mento/Consejo ${ }^{17}$, y en una Sentencia también anterior a la entrada en vigor de la Carta, el Tribunal, dijo que «...respecto a la Carta, fue proclamada solemnemente por el Parlamento, el Consejo y la Comisión en Niza el 7 de diciembre de 2000. Aunque esta Carta no constituye un instrumento jurídico vinculante, el legislador comunitario ha querido reconocer su importancia al afirmar, en el segundo considerando de la Directiva, que ésta observa los principios reconocidos no sólo por el artículo 8 del CEDH, sino también por la Carta. Por otra parte, el objetivo principal de la Carta, como se desprende de su preámbulo, es reafirmar «los derechos que emanan en particular de las tradiciones constitucionales y las obligaciones internacionales comunes a los Estados miembros, del [CEDH], de las Cartas Sociales adoptadas por la Unión y por el Consejo de Europa, así como de la jurisprudencia del Tribunal de Justicia [...] y del Tribunal Europeo de Derechos Humanos» "y volvió a citar expresamente los arts. 7 y 24 de la Carta.

A partir de diciembre de 2009, cuando la Carta ha adquirido fuerza jurídica vinculante igual a la de los Tratados, el Tribunal ha aplicado directamente la Carta, al interpretar el derecho de la Unión como, por ejemplo, en el caso Deticek, donde interpreta el alcance del artículo 20 del Reglamento n. ${ }^{\circ} 2201 / 2003^{18}$, en relación con el art. 24 de la Carta ${ }^{19}$, o como en el caso Volker und Markus Schecke y Eifert ${ }^{20}$, donde interpreta la validez de algunos artículos de los diversos Reglamentos sobre la financiación de la política agrícola común, de publicación de información sobre los beneficiarios de fondos del Fondeo Europeo Agrícola de Garantía y del Fondo Europeo Agrícola de Desarrollo Rural, así como de la Directiva sobre la conservación de datos generados o tratados en la prestación de servicios de comunicaciones electrónicas de acceso público o de redes públicas de comunicaciones ${ }^{21}$, en relación con los artículos 7 (respeto de

17 Sentencia de 27 de junio de 2006, Parlamento/Consejo, C-540/03, Rec. p. I-5769, apartados 38 y 58 .

18 Reglamento (CE) n. ${ }^{\circ} 2201 / 2003$ del Consejo, de 27 de noviembre de 2003, relativo a la competencia, el reconocimiento y la ejecución de resoluciones judiciales en materia matrimonial y de responsabilidad parental, por el que se deroga el Reglamento (CE) n. ${ }^{\circ}$ 1347/2000 (DO L 338, p. 1).

19 Sentencia de 23 de diciembre de 2009, Deticek, C-403/09 PPU, Rec. p. I-0000, apartados 53-55.

20 Sentencia de 9 de noviembre de 2010, Volker und Markus Schecke y Eifert, C-92/09 y C-93/09, Rec. p. I-0000, apartados 45-89.

21 En concreto, los artículos 42, punto 8 ter, y 44 bis del Reglamento (CE) n. ${ }^{\circ}$ 1290/2005 del Consejo, de 21 de junio de 2005, sobre la financiación de la política agrícola común (DO L 209, p. 1), en su versión modificada por el Reglamento (CE) n. ${ }^{\circ} 1437 / 2007$ del Consejo, de 26 de noviembre de 2007 (DO L 322, p. 1) (en lo suceISSN: 1134 - 993X, Núm. 45/2011, Bilbao, págs. 161-189 
la vida privada y familiar) y 8 (protección de datos de carácter personal) de la Carta.

\section{La «modesta» configuración de la protección de los consumidores en la Carta}

Una vez situados en el contexto de la Carta, analicemos brevemente cómo se diseña en ella la estrategia de la protección de los consumidores, donde hay que matizar también algunas cosas. El artículo 38 de la Carta se sitúa dentro del Título IV, denominado "Solidaridad» 22 . En este título aparecen recogidos algunos de los denominados «derechos de tercera generación» como, por ejemplo, el acceso a los servicios de interés económico general (art. 36) y la protección del medio ambiente (art. 37), que le anteceden. El artículo 38, el último de este Título IV, dice que «en las políticas de la Unión se garantizará un nivel elevado de protección de los consumidores», si bien jurídicamente hablando y como ya hemos visto anteriormente, no se trata de un auténtico derecho sino de un principio, lo que ciertamente limita su eficacia jurídica.

sivo, «Reglamento n. $\left.{ }^{\circ} 1290 / 2005 »\right)$, y, por otra parte, a la validez del Reglamento (CE) n. ${ }^{\circ}$ 259/2008 de la Comisión, de 18 de marzo de 2008, por el que se establecen disposiciones de aplicación del Reglamento n. ${ }^{\circ}$ 1290/2005 en lo que se refiere a la publicación de información sobre los beneficiarios de fondos procedentes del Fondo Europeo Agrícola de Garantía (FEAGA) y del Fondo Europeo Agrícola de Desarrollo Rural (Feader) (DO L 76, p. 28), y de la Directiva 2006/24/CE del Parlamento Europeo y del Consejo, de 15 de marzo de 2006, sobre la conservación de datos generados o tratados en relación con la prestación de servicios de comunicaciones electrónicas de acceso público o de redes públicas de comunicaciones y por la que se modifica la Directiva 2002/58/CE (DO L 105, p. 54).

22 Sobre el art. 38 de la Carta, pueden consultarse: Benoît-Rohmer, F.: «Article 38», en AA.VV.: Comentary of the Charter of Fundamentals Rights of the European Union. Bruselas: Network of Independent Experts on Fundamental Rights, junio de 2006, pp. 318-321; López Escudero, M.: «Comentario al art. 38. Protección de los consumidores», En Mangas Martín, A. (dir.): Carta de los derechos fundamentales de la Unión Europea: comentario artículo por artículo, Bilbao: Fundación BBVA, 2008, pp. 633-641; Lucarelli, A.: «Art. 38». En Bifurco, R. / Cartabia, M. / Celotto, A.: L'Europa dei diritti. Commento alla Carta dei diritti fondamentali del'Unione Europea, Bolonia: II Mulino, 2002, pp. 266-272; Picod, F.: «Art. II-98», en Bourgorge-Larsen, L. / Levade, A. / Picod, F. (dirs.): Traité Établissant une Constitution pour l'Europe. Partie II: La Charte des droits fondamentaux de I'Union. Commentaire article per article, Bruselas: Bruylant, 2005, vol. II, pp. 494-502. 
En este sentido ocurre algo similar a lo que sucede con el art. 51 de la Constitución española de 197823, que recoge también la protección y defensa de los consumidores y usuarios ${ }^{24}$, pero la recoge no como un derecho fundamental sino como un principio rector de la política social y económica del capítulo III del Título I, lo que, como es de sobre conocido, supone un menor nivel de protección, pues, como dice el art. 53.3 del texto constitucional español, «el reconocimiento, el respeto y la protección de los principios reconocidos en el Capítulo III informarán la legislación positiva, la práctica judicial y la actuación de los poderes públicos. Sólo podrán ser alegados ante la Jurisdicción ordinaria de acuerdo con lo que dispongan las leyes que los desarroIlen».

En el caso del art. 38 de la Carta, se produce una situación similar pues, según el art. 52.5 de la misma, las disposiciones que contengan principios «... podrán aplicarse mediante actos legislativos y ejecutivos adoptados por las instituciones, órganos y organismos de la Unión, y por actos de los Estados miembros cuando apliquen el Derecho de la Unión en el ejercicio de sus competencias respectivas. Sólo podrán alegarse ante un órgano jurisdiccional en lo que se refiere a la interpretación y control de legalidad de dichos actos».

23 El artículo 51 de la Constitución española establece lo siguiente:

1. Los poderes públicos garantizarán la defensa de los consumidores y usuarios, protegiendo, mediante procedimientos eficaces, la seguridad, la salud y los legítimos intereses económicos de los mismos.

2. Los poderes públicos promoverán la información y la educación de los consumidores y usuarios, fomentarán sus organizaciones y oirán a éstas en las cuestiones que puedan afectar a aquellos, en los términos que la ley establezca.

3. En el marco de lo dispuesto por los apartados anteriores, la ley regulará el comercio interior y el régimen de autorización de productos comerciales.

24 Sobre la protección de los consumidores y usuarios en el derecho español, pueden consultarse, a título de ejemplo, las siguientes obras: Bercovitz Rodríguez-Cano, R.: Comentario del Texto Refundido de la Ley General para la defensa de los consumidores y usuarios y otras leyes complementarias. Real Decreto Legislativo 1/2007, Pamplona: Aranzadi, 2009; Castellanos Ruiz, E.: Régimen jurídico de los consumidores. Competencia judicial internacional y ley aplicable, Granada: Comares, 2010; Corchero, M. I Grande Murillo, A.: La protección de los consumidores, Pamplona: Aranzadi, 2007; Lasarte Álvarez, C.: Manual sobre protección de consumidores y usuarios, Madrid: Dykin-

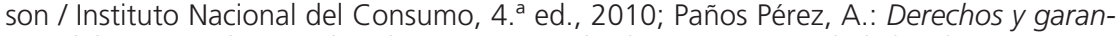
tías del consumidor en el ámbito contractual, Almería: Universidad de Almería, 2010. Pipaón Pulido, J.G.: Derechos de los consumidores y usuarios, Valladolid: Lex Nova, 2010; Rodríguez-Arana Muñoz, J. / Canosa Usera, R. / López Álvarez, L.F. / Meseguer Velasco, S. (coords.): Derecho de los consumidores y usuarios: una perspectiva integral, Madrid: Netbiblo, 2008. ISSN: 1134 - 993X, Núm. 45/2011, Bilbao, págs. 161-189 
La «explicación» que corresponde al art. 38 de la Carta, remite al art. 169 del Tratado de Funcionamiento de la Unión Europea (en adelante TFUE). Éste recoge el antiguo artículo 153 del Tratado de la Comunidad Europea, introducido por el Tratado de Maastricht. En resumen, este artículo viene a decir que, para promover los intereses de los consumidores y garantizarles un alto nivel de protección, la Unión contribuirá a proteger la salud, la seguridad y los intereses económicos de los consumidores, así como a promover su derecho a la información, a la educación y a organizarse para salvaguardar sus intereses. Para ello, la Unión contribuirá al logro de esos objetivos a través de: a) lo que se conocen como medidas relativas a la aproximación de las disposiciones legales, reglamentarias y administrativas de los Estados miembros que tengan por objeto el establecimiento y funcionamiento del mercado interior (art. 114 del TFUE / art. 26 TFUE); y b) medidas que apoyen, complementen y supervisen la política llevada a cabo por los Estados miembros, no obstando estas medidas para que cada uno de los Estados miembros mantenga y adopte medidas de mayor protección, siempre que sean compatibles con los Tratados y sean notificadas a la Comisión.

En realidad, nos encontramos aquí con una competencia compartida entre la Unión Europea y los Estados miembros —art. 4.2.f) del TFUE - y por eso el art. 12 del mismo Tratado establece la protección de los consumidores como un principio de carácter transversal que debe tenerse en cuenta en la definición y ejecución de otras políticas y acciones de la Unión. Como acabo de decir, el art. 38 de la Carta no configura propiamente la protección de los consumidores como un derecho subjetivo, sino como un principio, como una exigencia que debe respetar la Unión en la elaboración y aplicación de sus políticas y los Estados miembros cuando apliquen el derecho de las mismas sobre protección de los consumidores. Pero para producir efectos concretos respecto a los justiciables, se requiere la adopción de disposiciones normativas sobre la base del art. 169, por lo que el art. 38 no aporta ninguna posibilidad adicional de actuación para la Unión Europea.

Esto supone un cierto «jarro de agua fría», porque no se trata ni siquiera de lo que algún autor ha denominado «un derecho fundamental en vía de formación con contornos aún inciertos» ${ }^{25}$, a diferencia de lo que ocurre con otros derechos recogidos en la Carta, sino que sigue siendo un principio, con las limitaciones jurídicas que ello supone.

25 Picod, F.: op. cit., p. 496. 
Ahora bien, para ser totalmente justos, hay que decir que sólo el hecho de que haya sido incluido en el catálogo de derechos de solidaridad de la Carta ya es algo muy destacable, porque apuntala jurídicamente la actuación de la Unión Europea en defensa de los consumidores. Habrá que ver, sin embargo, ahora que la Carta ya es vinculante, qué alcance le da el Tribunal de Justicia al principio de protección de los consumidores del artículo 38 de la misma, pero sin perder de vista las limitaciones que en cuanto a los principios establece el art. 52.5 de la Carta.

\section{El «potencial» de la protección de los consumidores en el derecho derivado y en la jurisprudencia del Tribunal}

En todo caso, y aunque en la Carta, la protección de los consumidores es un principio y no un derecho, y a la espera de comprobar qué utilización de ese artículo de la Carta hace el Tribunal en su jurisprudencia, la protección de los consumidores está dando mucho más juego en el derecho derivado del que podría pensarse viendo la forma tan «modesta» en que se ha recogido en la Carta26.

En un principio, la actuación de la Comunidad Europea en materia de consumo se fundamentó jurídicamente en la armonización de legislaciones del mercado interior, adoptando una serie de Directivas sobre la materia. Por su parte, el Tratado de Maastricht estableció en 1992 un base jurídica específica para la protección de los consumidores, que fue reforzada en el Tratado de Amsterdam y que se recogió en el art. 153 del Tratado de la Comunidad Europea, que ha recogido ahora el artículo 169 del TFUE. De hecho, se han venido aprobando distintos Programas de Acción comunitaria en el ámbito

26 Azparren Lucas, A.: «La protección de los consumidores en la Unión Europea», en Alvárez Conde, E. / Garrido Mayol, V.: Comentarios a la Constitución Europea, Valencia: Tirant lo Blanch, 2004, vol. 3 (políticas comunitarias, las finanzas de la Unión), pp. 71-102; Comisión Europea: Libro Verde sobre la revisión del acervo en materia de consumo, COM (2006), 744 final, 8 de febrero de 2007; Defalque, L.: "La protection des consommateurs. Une politique inachevée», en De Schutter, O. / Nihoul, P. (eds.): Une Constitution pour l'Europe. Réflexions sur les transformations de droit de l'Union Européenne, Bruxelles: Larcier, 2004, pp. 341 y ss; Esteban de la Rosa, F.: La protección de los consumidores en el mercado interior europeo. Granada: Comares, 2003; Ezquerra Ubero, J.J.: «El consumidor protegido por el derecho comunitario», en Canedo

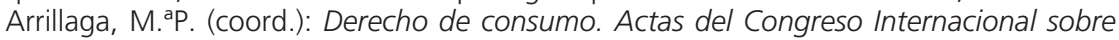
Derecho del Consumo, Valencia: Tirant lo Blanch, 2009; Méndez Pinedo, E. / Pappas, S.A.: «La protección de consumidores en la Unión Europea: hacia un derecho procesal comunitario de consumo», Madrid: Marcial Pons, 1999. ISSN: 1134 - 993X, Núm. 45/2011, Bilbao, págs. 161-189 
de la política de los consumidores, siendo el último el adoptado para el período 2007-201327.

Así que, además del derecho originario, recogido en los artículos 12 y 169 del TFUE y del art. 38 de la Carta, existe un importante acervo de derecho derivado en materia de protección de los consumidores en asuntos tales como, por ejemplo, las prácticas comerciales desleales de las empresas en sus relaciones con los consumidores del mercado interior, la publicidad engañosa, la responsabilidad por los daños causados por productos defectuosos, la seguridad general de productos, alimentos y piensos modificados genéticamente, las cláusulas abusivas en los contratos celebrados con consumidores, el etiquetado, presentación y publicidad de productos alimenticios, el etiquetado y embalaje de productos específicos y productos no alimenticios, etc.

Pero además de la legislación protectora de los consumidores, también la jurisprudencia del Tribunal de Justicia ha desarrollado una importante labor de defensa de los consumidores, estableciendo claramente cuál es el criterio de interpretación para determinar si una reglamentación de la Unión Europea establece un elevado nivel de protección de los derechos de los consumidores, que es justo lo que exige el art. 38 de la Carta: el parámetro a tener en cuenta para ello es el del consumidor medio, normalmente informado y razonablemente atento y perspicaz. ${ }^{28}$ En todo caso, el Tribunal ha interpretado el derecho comunitario derivado, y sobre todo las directivas referentes a la protección de los consumidores, intentando reforzar su efectividad, aunque no se trate de un derecho fundamental sino de un principio, así que la posible decepción inicial debe ser también matizada. Como ha escrito LÓPEZ ESCUDERO, siguiendo a PICOD, «el TJCE ha llevado a cabo, también, una interpretación de las directivas referentes a la protección de los consumidores tendente a reforzar su efectividad de forma parecida a lo que ocurre con los derechos fundamentales». ${ }^{29}$ Veamos por qué:

Para ilustrar esa clara tendencia a proteger siempre al consumidor, como parte más débil, me voy a centrar en algunas de las materias a la

27 Fue adoptado mediante la Decisión 1926/2006/CE del Parlamento Europeo y del Consejo, de 18 de diciembre de 2006 ( $D O$ L 404, de 30 de diciembre de 2006, p. 39).

28 STJ de 16 de julio de 1998, Gut Springenheide y Tusky, C-210/96, Rec., p. I-4657, apartado 31.

29 López Escudero, M. «Comentario al art. 38. Protección de los consumidores», en Mangas Martín, A. (dir.): Carta de los derechos fundamentales de la Unión Europea: comentario artículo por artículo, Bilbao: Fundación BBVA, 2008, p. 638, que cita a su vez a Picod, F.: "Art. II-98», en Bourgorge-Larsen, L. / Levade, A. / Picod, F. (dirs.): Traité Établissant une Constitution pour l'Europe. Partie II: La Charte des droits fondamentaux de I'Union. Commentaire article per article, Bruselas: Bruylant, 2005, vol. II, p. 499. 
que antes he aludido. El elemento común en todos estos casos es que el Tribunal ha partido de la idea de que el consumidor se halla en una situación de inferioridad respecto al profesional, tanto en la capacidad de negociación como en el nivel de información, lo que le lleva muchas veces a adherirse a las condiciones redactadas por el profesional sin poder influir en su contenido. Para hacer frente a ese desequilibrio, el Tribunal ha establecido que dicha situación sólo puede compensarse mediante una intervención positiva, ajena a las partes del contrato, esto es, mediante la intervención del juez, que no se limita a observar una conducta imparcial, como venía siendo el rol propio de un juez en asuntos civiles y mercantiles en las distintas tradiciones jurídicas europeas, sino que se implica claramente para favorecer a la parte más débil30. Así, frente a la regla general de la inexistencia por parte de los jueces nacionales de una obligación general de apreciación de oficio de los derechos conferidos a los individuos por el ordenamiento comunitario, regla que contaba con una consolidada jurisprudencia ${ }^{31}$, el Tribunal de Justicia ha elaborado en su jurisprudencia una excepción a esa regla general en relación, precisamente, con la protección de consumidores.

En primer lugar lo hizo respecto de la Directiva 93/13/CEE sobre cláusulas abusivas en los contratos celebrados con los consumidores 32 , declarando que una interpretación conjunta de los artículos 3.1. y 4.1 de dicha Directiva es la que permite definir los criterios generales que permiten apreciar la naturaleza abusiva de las cláusulas contractuales sujetas a las disposiciones de la Directiva. ${ }^{33}$ Veamos algunos de sus pronunciamientos más importantes en este ámbito:

a) En la Sentencia «Océano Grupo y Salvat Editores», el Tribunal dijo que el sistema de protección establecido por esta Directiva se basa en la idea de que el consumidor se halla en una situación

30 STJ de 9 de noviembre de 2010, VB Pénzügyi Lízing, C-137/08, Rec. p. I-0000, apartado 48.

31 STJ de 14 de diciembre de 1995, Peterbroeck, C-312/93, Rec. p. I-4599, apartado 12; 14 de diciembre de 1995, Van Schijndel y van Veen, C-430/93 y C-431/93, Rec. p. I-4705, apartado 17; de 16 de mayo de 2000, Preston y otros, C-78/98, Rec. p. I-3201, apartado 31; 9 de diciembre de 2003, Comisión /Italia, C-129/00, Rec. p. 1-14637, apartado 25 y 7 de junio de 2006, Van der Weerd y otros (C-222/05 a C-225/05, Rec. p. 1-4233, apartado 28.

32 Directiva 93/13/CEE del Consejo, de 5 de abril de 1993, sobre cláusulas abusivas en los contratos celebrados con consumidores ( $D O L$ L5, p. 29).

33 SSTJ de 7 de mayo de 2002, Comisión /Suecia, C-478/99, Rec. p. 1-4147, apartados 11 y 17; de 1 de abril de 2004, Freiburger Kommunalbauten, C-237/02, Rec. p. I-3403, apartados 18,19 y 21; de 3 de junio de 2010, Caja de Ahorros y Monte de Piedad de Madrid, C-484/08, Rec. p. I-0000, apartado 33. 
de inferioridad respecto al profesional, en lo referido tanto a la capacidad de negociación como al nivel de información, lo que le lleva a adherirse a las condiciones redactadas de antemano por el profesional, sin poder influir en el contenido de éstas. Y señaló también que existe un riesgo nada desdeñable, debido, entre otras cosas a la ignorancia, de que el consumidor no invoque el carácter abusivo de la cláusula esgrimida en su contra, de tal manera que, según el Tribunal, sólo podrá alcanzarse una protección efectiva del consumidor si el juez nacional está facultado para apreciar de oficio el carácter abusivo de dicha cláusula. ${ }^{34}$

b) De igual modo, en la Sentencia "Cofidis», subrayó que esa facultad reconocida al juez de examinar de oficio el carácter abusivo de una cláusula del contrato, se considera necesaria para garantizar al consumidor una protección efectiva, habida cuenta del riesgo nada desdeñable de qué este ignore sus derechos o encuentre dificultades para ejercitarlos. ${ }^{35}$

c) Asimismo, en la Sentencia "Mostaza Claro», el Tribunal extendió esta protección a aquellos supuestos en los que el consumidor que haya celebrado con un profesional un contrato en el que figure una cláusula abusiva, no invoque el carácter abusivo de la citada cláusula, bien porque ignore sus derechos, o bien porque los gastos que acarrea el ejercicio de una acción ante los Tribunales le disuadan de defenderlos. Al aludir al art. 6.1 de la Directiva, el Tribunal dijo que con ella se trata de reemplazar el equilibrio formal que el contrato establece entre los derechos y obligaciones de las partes por un equilibrio real que pueda restablecer la igualdad entre éstas. ${ }^{36}$

d) En la Sentencia «Pannon GSM», el Tribunal consideró que una cláusula contenida en un contrato celebrado entre un consumidor y un profesional, que ha sido incluida sin haber sido objeto de negociación individual y que atribuye competencia exclusiva al Tribunal en cuya circunscripción está situado el domicilio del profesional, puede ser considerada abusiva. ${ }^{37} \mathrm{Y}$ ello porque la

34 STJ de 27 de junio de 2000, Océano Grupo Editorial y Salvat Editores, C-240/98 a C-244/98, Rec. p. I-4941, apartados 25-27.

35 STJ de 21 de noviembre de 2002, Cofidis, C-473/00, Rec. p. I-10875, apartados $32-33$ y 38.

36 STJ de 26 de octubre de 2006, Mostaza Claro, C-168/05, Rec. p. I-10421, apartados 28-29. La misma argumentación se recoge en la Sentencia de 9 de noviembre de 2010, VB Pénzügyi Lízing, C-137/08, Rec. p. I-0000, apartado 47.

37 Sentencia de 4 de junio de 2009, Pannon GSM, C-243/08, Rec. p. I-4713, apartado 44 . 
obligación de someterse a la competencia exclusiva de un Tribunal que puede estar lejos de su domicilio, puede hacer más difícil la comparecencia del consumidor. Sobre todo en los litigios de escasa cuantía, cuando los gastos correspondientes a la comparecencia del consumidor pueden resultar disuasorios y hacer que éste renuncie a interponer el recurso judicial y a defenderse. Y además, ese tipo de cláusulas permiten al profesional agrupar todos los procedimientos judiciales que genera su actividad profesional en un solo Tribunal, que no es el que corresponde al consumidor, lo que facilita la organización de la comparecencia de dicho profesional, al mismo tiempo que hace que ésta sea menos gravosa. ${ }^{38}$

e) En la Sentencia «Asturcom Telecomunicaciones», y en un caso en que la demandada había permanecido absolutamente pasiva durante los distintos procedimientos referentes al litigio entre ella y la compañía demandante («Asturcom»), no atacando ni siquiera el laudo arbitral, cuando podía haber invocado el carácter abusivo de una cláusula arbitral, de tal manera que, al no hacer nada, el laudo había adquirido fuerza de cosa juzgada, pues bien, incluso en ese caso, el Tribunal dijo que en la medida establecida en una legislación de un país miembro que establezca que el juez nacional que conozca de una demanda de ejecución forzosa de un laudo arbitral firme debe, con arreglo a las normas procesales internas, apreciar de oficio la contrariedad de una cláusula arbitral con las normas nacionales de orden público, está igualmente obligado a apreciar de oficio el carácter abusivo de dicha cláusula desde el punto de vista del artículo 6 de la Directiva, tan pronto como disponga de los elementos de hecho y de derecho necesarios para ello. ${ }^{39}$

En segundo lugar, el Tribunal aplicó esta misma jurisprudencia en relación con la Directiva 87/102/CEE del Consejo, de 22 de diciembre de 1986, relativa a la aproximación de las disposiciones legales, reglamentarias y administrativas de los Estados miembros en materia de cré-

38 Sentencia de 9 de noviembre de 2010, VB Pénzügyi Lízing, ya citada, apartados 53-55, y que se remite a la Sentencia de 27 de junio de 2000, Oceáno Grupo y Salvat editores, también citada, apartados 22 y 23.

39 Sentencia de 6 de octubre de 2009, Asturcom Telecomunicaciones, C-40/08, Rec. p. I-9579, apartados 53 y 59, que se remite a su vez a la Sentencia de 4 de junio de 2009, Pannon GSM, C-243/08, Rec. p. I-4713, apartado 32. 
dito al consumo. ${ }^{40}$ En la Sentencia «Rampion y Godard», el Tribunal afirmó que esta Directiva debía interpretarse en el sentido de que permitía al órgano jurisdiccional nacional aplicar de oficio las disposiciones que adaptan el derecho interno al art. 11.2 de la Directiva. Dicho artículo permitía al consumidor dirigirse contra el prestamista, estableciendo los Estados miembros en qué medida y bajo qué condiciones podía ejercitarse ese derecho. El Tribunal dijo que esta Directiva pretendía crear un mercado común del crédito al consumo y proteger a los consumidores que contrajesen dichos créditos, atribuyéndoles respecto al prestamista derechos adicionales en relación con los que normalmente tendría contra él y contra el proveedor de bienes y servicios. Y declaró que este objetivo no podría alcanzarse efectivamente si pesara sobre el consumidor la carga de invocar por sí mismo el derecho a dirigirse contra el prestamista, en particular, debido al riesgo nada despreciable de que el consumidor ignorase sus derechos o encontrase dificultades para ejercitarlos. ${ }^{41}$

En tercer lugar, podemos analizar lo ocurrido con la Directiva 85/77CEE del Consejo, de 20 de diciembre de 1985, referente a la protección de los consumidores en el caso de contratos negociados fuera de los establecimientos comerciales ${ }^{42}$ y más en concreto, de su artículo 4 que obliga al comerciante a informar por escrito al consumidor sobre su derecho a rescindir el contrato durante los plazos definidos en el art. 5, así como sobre el nombre y dirección de una persona con respecto a la cual pueda ejercer dicho derecho y que establece que los Estados miembros procurarán que la legislación nacional prevea medidas adecuadas que tiendan a proteger al consumidor en caso de que no se haya proporcionado dicha información.

En relación con la aplicación de esta Directiva, el Tribunal dijo en la Sentencia «Martín Martín», que el artículo 4 de la Directiva no se opone a que un órgano jurisdiccional nacional declare de oficio la nulidad de un contrato comprendido en el ámbito de aplicación de dicha Direc-

40 Directiva 87/102/CEE del Consejo de 22 de diciembre de 1986, relativa a la aproximación de las disposiciones legales, reglamentarias y administrativas de los Estados miembros en materia de crédito al consumo ( $D O L$ 42, p. 48). Esta Directiva fue derogada por la Directiva 2008/48/CE del Parlamento Europeo y del Consejo de 23 de abril de 2008, relativa a los contratos de crédito al consumo y por la que se deroga la Directiva 87/102/CEEE (DO L 133, p. 66).

41 STJ de 4 de octubre de 2007, Rampion y Godard, C-429/05, Rec. p. I-8017, apartados 59, 64, 65 y 69 .

42 Directiva 85/77CEE del Consejo, de 20 de diciembre de 1985, referente a la protección de los consumidores en el caso de contratos negociados fuera de los establecimientos comerciales ( $D O \mathrm{~L}$ 372, p. 31). 
tiva, por no haberse informado al consumidor de su derecho de rescisión, aun cuando éste no haya invocado en ningún momento esa nulidad ante los órganos jurisdiccionales competentes, pues el régimen de protección introducido por la Directiva no sólo implica que el consumidor, como parte débil, disponga de un derecho a rescindir el contrato, sino también que tenga pleno conocimiento de sus derechos, siendo informado por escrito, ya que esa obligación de información ocupa un lugar central en la estructura general de la Directiva como garantía esencial de un ejercicio efectivo del derecho de revocación y, por tanto, del efecto útil de la protección de los consumidores a la que aspira el legislador comunitario. ${ }^{43}$

De hecho, como dijo el Tribunal en la Sentencia «Heininger» ${ }^{44}$ y ha vuelto a repetir en la Sentencia «Friz» ${ }^{45}$, existe una reiterada jurisprudencia que afirma que las excepciones a las normas de Derecho de la Unión Europea destinadas a proteger a los consumidores, han de interpretarse estrictamente. El principio general de la normativa de la Unión Europea en este ámbito es siempre la protección del consumidor, por ser la parte más débil. Y esta idea la ha repetido una y otra vez el Tribunal, por ejemplo, cuando se ha referido al Reglamento (CE) 44/2001 del Consejo, de 22 de diciembre de 2000, relativo a la competencia judicial, el reconocimiento y la ejecución de resoluciones judiciales en materia civil y mercantil|46, y más en concreto a su considerando n. ${ }^{\circ} 13$, que establece que, en cuanto a los contratos celebrados por los consumidores, es oportuno proteger a la parte más débil mediante reglas de competencia más favorables a sus intereses de lo que disponen las reglas generales, y al referirse al art. 15.1.c) del Reglamento, ha dicho que ocupa el mismo lugar y cumple la misma función de protección de la parte más débil del contrato, que el art. 13.1.3. ${ }^{\circ}$ del Convenio de Bruselas ${ }^{47}$, respecto del cual, el Tribunal ya había dicho que la función

43 Sentencia de 17 de diciembre de 2009, Martín Martín, C-227/08, Rec. p. I-0000, apartados 26, 27 y 36 .

44 Sentencia de 13 de diciembre de 2001, Heininger, C-481/99, Rec. p. I-9945, apartado 31.

45 Sentencia de 15 de abril de 2010, E. Friz, C-215/08, Rec. p. I-0000, apartado 32.

46 Reglamento (CE) 44/2001 del Consejo, de 22 de diciembre de 2000, relativo a la competencia judicial, el reconocimiento y la ejecución de resoluciones judiciales en materia civil y mercantil (DO $2001 \mathrm{~L}, 12$, p. 1). Hay que tener en cuenta también el Reglamento (CE) 593/2008, del Parlamento Europeo y del Consejo, de 17 de junio de 2008, sobre ley aplicable a las obligaciones contractuales (Roma I), (DO L, 177, p. 6).

47 El Convenio de Bruselas, es el nombre por el que es conocido el Convenio de 27 de septiembre de 1968 relativo a la competencia judicial y a la ejecución de resoluciones judiciales en materia civil y mercantil (texto consolidado publicado en el DO, 1998, C 27, 
del régimen particular que establecen las disposiciones del Convenio de Bruselas sobre la competencia en materia de contratos celebrados con consumidores, consiste en garantizar una protección adecuada al consumidor en cuanto parte del contrato que se considera económicamente más débil y jurídicamente menos experta que su cocontratante profesional. ${ }^{48}$

\section{Conclusión}

En definitiva, aunque la inclusión de la protección de los consumidores en el artículo 38 de la Carta de los Derechos Fundamentales se haya producido como un principio y no como un auténtico derecho, con las consecuencias jurídicas que ello tiene según el artículo 54.5 de la misma, hasta ahora, los actos legislativos y ejecutivos adoptados por las instituciones de la Unión y los actos de los Estados miembros adoptados al aplicar el Derecho de la Unión (que incluso en algún caso concreto han optado por regulaciones más favorables a los consumidores que las establecidas por las Directivas que tenían que «trasponer» a su derecho interno) han marcado una tendencia muy clara hacia una protección cada vez mayor del consumidor. Y en el caso del Tribunal, éste incluso ha roto una lanza a favor de los consumidores, reconociendo excepciones a principios generales del derecho de la Unión, que le han situado en la vanguardia de la protección de este colectivo. Si eso ha ocurrido antes de que la Carta fuese jurídicamente vinculante, es previsible que con apoyo en el principio del art. 38 de la Carta, ahora ya en vigor y equiparada a los Tratados, tanto los actos de las instituciones de la Unión, como los de los Estados miembros al aplicar derecho de la misma y la jurisprudencia del Tribunal, vayan más allá en la garantía de un nivel elevado de protección de los consumidores. Por eso, volviendo al símil futbolístico de la liga europea con la que comenzaba este artículo, creo que puede decirse que la protección de los consumidores en la Carta de los Derechos Fundamentales de la Unión Europea, aunque inicialmente pueda parecer modesta, tiene mucho potencial.

p. 1). Al entrar en vigor el Reglamento 44/2001, este Reglamento sustituyó al Convenio de Bruselas en las relaciones entre Estados miembros, con la excepción de Dinamarca.

48 SSTJ de 20 de enero de 2005, Gruber, C-464/01, Rec. p. I-439, apartado 34; de 20 de enero de 2005, Engler, C-27/02, Rec. p. I-481, apartado 39; de 14 de mayo de 2009, Ilsinger, C-180/06, Rec. p. I-3961, apartado 41 y de 7 de diciembre de 2010, Pammer y Hotel Alpenhof, C-585/08 y C-144/09, Rec. p. I-0000, apartados 57 y 58. 


\section{Vl. Bibliografía}

Alonso García, R.: «La Carta de los derechos fundamentales de la Unión Europea», Gaceta Jurídica de la CE, n. ${ }^{\circ} 209$ (2000), pp. 3-17.

- I Sarmiento, D.: La Carta de los Derechos Fundamentales de la Unión Europea. Explicaciones, concordancias, jurisprudencia, Cizur Menor: ThomsonCivitas, 2006.

Alston, P. / Bustelo, M.R. / Heenan, J. (dirs.): L'Union Européenne et les droits de l'homme, Bruxelles: Bruylant, 2001.

Andrés Sáenz de Santamaría, P.: «La Carta de los Derechos Fundamentales de la Unión Europea en la práctica española», Revista de Derecho de la Unión Europea, n. 15 (2008), pp. 233-255.

ArnulL, A. «From Charter to Constitution and beyond: fundamental rights in the new European Union», Public Law, 2003 (winter), pp. 774-793.

Arzoz Santisteban, X.: «La relevancia del derecho de la Unión Europea para la interpretación de los derechos fundamentales constitucionales», Revista Española de Derecho Constitucional, n. ${ }^{\circ} 74$ (2005), pp. 63-110.

AsHIAGBOR, D.: «Economic and social rights in the European Charter of Fundamental Rights», European Human Rights Law Review, n. 1 (2004), pp. 6272.

H, A.: «La protección de los consumidores en la Unión Europea», en Álvarez Conde, E. / GarRido Mayol, V.: Comentarios a la Constitución Europea, Valencia: Tirant lo Blanch, 2004, vol. 3 (políticas comunitarias, las finanzas de la Unión), pp. 71-102.

Azı, M.: The impact of European rights on national legal cultures, Oxford: Hart, 2004.

BenoîT-ROHMER, F.: «Article 38», en AA.VV.: Comentary of the Charter of Fundamentals Rights of the European Union. Bruselas: Network of Independent Experts on Fundamental Rights, junio de 2006, pp. 318-321.

Bercovitz Rodríguez-Cano, R.: Comentario del Texto Refundido de la Ley General para la defensa de los consumidores y usuarios y otras leyes complementarias. Real Decreto Legislativo 1/2007, Pamplona: Aranzadi, 2009.

BogDANDY, A. von, "The European Union as a human rights organization: human rights and the core of the European Union», Common Market Law Review, vol. 37, n. ${ }^{\circ} 6$ (2000) , pp. 1.307-1.338.

CAmpos SÁnchez-Bordona, M.: «Los jueces nacionales ante la Carta de derechos fundamentales de la Unión Europea: algunas cuestiones que suscita el título VII de la Carta», Noticias de la Unión Europea, n. ${ }^{\circ} 291$ (abril de 2009), pp. 21-29.

Canedo Arrillaga, J.R. / Gordillo Pérez, L.I.: «Los derechos fundamentales en la Unión Europea a la espera de Lisboa», Cuadernos Europeos de Deusto, n. 39 (2008), pp. $27-59$.

Castellanos Ruiz, E.: Régimen jurídico de los consumidores. Competencia judicial internacional y ley aplicable, Granada: Comares, 2010.

COMISIÓN EUROPEA: Libro Verde sobre la revisión del acervo en materia de consumo, COM (2006), 744 final, 8 de febrero de 2007. 
Corchero, M. / Grande Murillo, A.: La protección de los consumidores, Pamplona: Aranzadi, 2007.

CoRRIENTE CóRdobA, J.A.: «La protección de los derechos económicos, sociales y culturales en la Carta de los Derechos Fundamentales de la Unión Europea», Anuario de Derecho Europeo, n. ${ }^{\circ} 2$ (2002), pp. 117-135.

DeFAlQue, L.: «La protection des consommateurs. Une politique inachevée», en De Schutter, O. / Ninoul, P. (eds.): Une Constitution pour l'Europe. Réflexions sur les transformations de droit de l'Union européenne, Bruxelles: Larcier, 2004, pp. 341 y ss.

DíAz CREGO, M.: «Los derechos fundamentales en la Unión Europea: de la carta a la Constitución», Revista Española de Derecho Constitucional, n. ${ }^{\circ} 74$ (2005), pp. 139-175.

- : Protección de los derechos fundamentales en la Unión Europea y en los Estados miembros, Madrid: Reus, 2009.

Douglas-SCOTT, S.: «The Charter of Fundamental Rights as a constitutional document», European Human Law Review, n. 1 (2004), pp. 37-50.

DUTHEIL DE LA ROCHERE, J.: «La Chartre des droits fondamentaux de I'Union Européenne: quelle valeur ajoutée, quel avenir?», Revue du Marché Commun et de l'Union Européenne, n. 443 (2000), pp. 674-680.

EHLERS, D.: European fundamental rights and freedoms, Berlin: De Gruyter, 2007.

ESTEBAN DE LA ROSA, F.: La protección de los consumidores en el mercado interior europeo. Granada: Comares, 2003.

EZQUERRA UBERO, J.J.: «El consumidor protegido por el derecho comunitario», en Canedo Arrillaga, M. ${ }^{a}$ P. (coord.): Derecho de consumo. Actas del Congreso Internacional sobre Derecho del Consumo, Valencia: Tirant lo Blanch, 2009.

Fernández TomÁs, A.: "La Carta de derechos fundamentales de la Unión Europea: un nuevo hito en el camino de la protección», Gaceta Jurídica de la Unión Europea y de la competencia, n. ${ }^{\circ} 214$ (2001), pp. 15-30.

- : La Carta de los derechos fundamentales de la Unión Europea, Valencia: Tirant lo Blanch, 2002.

García Roca, J. / Aguilera VAqués, M.: Integración europea a través de derechos fundamentales: de un sistema binario a otro integrado, Madrid: Centro de Estudios Políticos y Constitucionales, 2009.

GIL y GIL, J.L. / Ushakova, T.: «Los derechos sociales en la Carta de los Derechos Fundamentales de la Unión Europea», Relaciones laborales: Revista crítica de teoría y práctica, n. 2 (2002), pp. 1.319-1.344.

Herrero de la Fuente, A. (ed.), La Carta de Derechos Fundamentales de la Unión Europea. Una perspectiva pluridisciplinar, Zamora: Fundación Rei Alfonso Henriques, 2003.

HeRVEY, T. / KenNeR, J.: Economic and social rights under the EU charter of fundamental rights: a legal perspective, Oxford: Hart, 2006.

$\mathrm{KRISCH}, \mathrm{N}$ : : "The open architecture of European human rights law», The Modern Law Review, vol. 71, n. ${ }^{\circ} 2$ (2008), pp. 183-216.

LaRRAZABAl BASÁÑEZ, S.: "La Constitución económica de la Unión Europea y el difícil equilibrio entre las libertades económicas y los derechos sociales», 
Boletín de la Asociación Internacional de Derecho Cooperativo, n. ${ }^{\circ} 44$ (2010), pp. 221-250.

LASARTE ÁlvaReZ, C.: Manual sobre protección de consumidores y usuarios, Madrid: Dykinson / Instituto Nacional del Consumo, 4. ${ }^{\text {a }}$ ed., 2010.

LINDE PANIAGUa, E.: «El ámbito de aplicación: el talón de Aquiles de la Carta de los Derechos Fundamentales de la Unión Europea», Revista de Derecho de la Unión Europea, n. 15 (2008), pp. 27-44.

liñán Nogueras, D.J. / Martín Rodríguez, P.J.: «Reflexiones sobre los derechos fundamentales de la Unión Europea a la luz del Tratado de Lisboa», en Derecho internacional y comunitario ante los retos de nuestro tiempo. Homenaje a la Profesora Victoria Abellán Honrubia, Madrid: Marcial Pons, 2009, pp. 1.053 y ss.

LÓPEZ ESCUDERO, M.: «Comentario al art. 38. Protección de los consumidores», en Mangas Martín, A. (dir.): Carta de los derechos fundamentales de la Unión Europea: comentario artículo por artículo, Bilbao: Fundación BBVA, 2008, pp. 633-641.

lucarelli, A.: «Art. 38», en Bifurco, R. / Cartabia, M. / Celotto, A.: L'Europa dei diritti. Commento alla Carta dei diritti fondamentali del'Unione Europea, Bolonia: Il Mulino, 2002, pp. 266-272.

Mangas Martín, A. (dir.): Carta de los derechos fundamentales de la Unión Europea: comentario artículo por artículo, Bilbao: Fundación BBVA, 2008.

Mangas Martín, A. / Liñán Nogueras, D.J.: Instituciones y Derecho de la Unión Europea, Madrid: Tecnos, 6. ${ }^{a}$ ed., 2010, pp. 121-141.

Martín y Pérez de Nanclares, J.: "The protection of human rights in the European Union». En Gómez ISA, F. / DE FeYter, K. (dirs.): International Human Rights Law in a Global Context, Bilbao: Universidad de Deusto, 2009, pp. 777 y ss.

MAYER, F.C.: "La Charte européenne des droits fondamentaux et la Constitution européenne», Revue Trimestrielle de Droit Européen, vol. 39 (2003-2), pp. 176 y ss.

Méndez Pinedo, E. / Pappas, S.A.: «La protección de consumidores en la Unión Europea: hacia un derecho procesal comunitario de consumo», Madrid: Marcial Pons, 1999.

Monereo Pérez, J.L.: La protección de los derechos fundamentales: el modelo europeo, Albacete: Bomarzo, 2009.

MuRRAY, J.L.: "Fundamental rights in the European Community legal order», Fordham International Law Journal, vol. 32, n. ${ }^{\circ} 2$ (2009), pp. 531-550.

ORdóñez Solís, D.: «El Tratado de Lisboa, los nuevos Estatutos de Autonomía y la protección judicial de los derechos fundamentales», Noticias de la Unión Europea, n. 291 (abril de 2009) — monográfico sobre el Tratado de Lisboa-, pp. 5-20.

Ortiz Herrera, S.: Los Derechos Fundamentales en los Tratados Europeos. Evolución y situación actual, Madrid: CEU Ediciones, 2010.

Palacio González, J.: «La protección de los derechos fundamentales por el Tribunal de Justicia de la UE: alcance y consecuencias de la futura adhesión ISSN: 1134 - 993X, Núm. 45/2011, Bilbao, págs. 161-189 
de la UE al Convenio Europeo», Cuadernos Europeos de Deusto, n. ${ }^{\circ} 40$ (2009), pp. 161-179.

Paños Pérez, A.: Derechos y garantías del consumidor en el ámbito contractual, Almería: Universidad de Almería, 2010.

Pardo Getino, L.A.: «Los derechos humanos en el marco de la última reforma de la Unión Europea», Revista General de Derecho Europeo, n. ${ }^{\circ} 21$ (2010).

Parejo Navajas, T.: «La Carta de los derechos fundamentales de la Unión Europea», Derechos y libertades: Revista del Instituto Bartolomé de las Casas, año 14, n. ${ }^{\circ} 22$ (2010), pp. 205-239.

Pérez Pérez, G.: «La problemática de los derechos sociales en la Carta de los Derechos Fundamentales de la Unión Europea», Cuestiones constitucionales: Revista mexicana de Derecho constitucional, n. ${ }^{\circ} 18$ (2008).

PI Llorens, M.: La Carta de los Derechos Fundamentales de la Unión Europea, Barcelona: Universitat, 2001.

Picod, F.: «Art. II-98», en Bourgorge-Larsen, L. / Levade, A. / Picod, F. (dirs.): Traité Établissant une Constitution pour l'Europe. Partie II: La Charte des droits fondamentaux de I'Union. Commentaire article per article, Bruselas: Bruylant, 2005, vol. II, pp. 494-502.

PIPAÓN PULIDO, J.G.: Derechos de los consumidores y usuarios, Valladolid: Lex Nova, 2010.

RideAu, J.: Les droits fondamentaux dans I'Union européenne. Dans le sillage de la Constitution européenne, Bruxelles: Bruylant, 2010.

Rodriguez-Arana Muñoz, J. / Canosa Usera, R. / Lopez Álvarez, L.F. / Meseguer VeLAsCo, S. (coords.): Derecho de los consumidores y usuarios: una perspectiva integral, Madrid: Netbiblo, 2008.

Rodríguez Bereijo, A.: «La Carta de los derechos fundamentales de la Unión Europea», Noticias de la Unión Europea, n.o 192 (2001), pp. 9-20.

RodríGuez García, L.F.: «La recepción de la Carta de Derechos Fundamentales de la Unión Europea en la legislación y la jurisprudencia españolas antes de su vigencia», en GARCía RoCA, F.J. (coord.): Treinta años de Constitución, Valencia: Tirant lo Blanch, 2010, pp. 561-584.

Ruiz Miguel, C.: Estudios sobre la Carta de los derechos fundamentales de la Unión Europea, Santiago de Compostela: Universidade de Santiago de Compostela, 2004.

SkouRIS, W. I FAVReAu, B.: Le charte des droits fondamentaux de l'Union Européenne après le traité de Lisbonne, Bruxelles: Bruylant, 2010.

Tizzano, A.: «La protection des droits fondamentaux en Europe. La Cour de justice et les jurisdictions constitutionnelles nationales», Revue du droit de I'Union Européenne, n. ${ }^{\circ} 1$ (2006), pp. 9-21.

TUR Ausina, R.: «Luces y sombras de los derechos sociales en la Carta de los Derechos Fundamentales de la Unión Europea», Revista Europea de Derechos Fundamentales, n. ${ }^{\circ} 13$ (2009), pp. 323-349.

VIToRINO, A.: «La Charte des droits fondamentaux de I'Union européenne», Revue du Droit de l'Union Européenne, n. 1 (2000), pp. 27-64. 


\section{Jurisprudencia seleccionada del Tribunal de Justicia en materia de protección al consumidor}

Sentencia de 16 de julio de 1998, Gut Springenheide y Tusky, C-210/96, Rec., p. I-4657.

Sentencia de 27 de junio de 2000, Océano Grupo Editorial y Salvat Editores, C-240/98 a C-244/98, Rec. p. I-4941.

Sentencia de 13 de diciembre de 2001, Heininger, C-481/99, Rec. p. I-9945.

Sentencia de 7 de mayo de 2002, Comisión/Suecia, C-478/99, Rec. p. I-4147.

Sentencia de 21 de noviembre de 2002, Cofidis, C-473/00, Rec. p. I-10875.

Sentencia de 1 de abril de 2004, Freiburger Kommunalbauten, C-237/02, Rec. p. I-3403.

Sentencia de 20 de enero de 2005, Gruber, C-464/01, Rec. p. I-439.

Sentencia de 20 de enero de 2005, Engler, C-27/02, Rec. p. I-481.

Sentencia de 26 de octubre de 2006, Mostaza Claro, C-168/05, Rec. p. I-10421.

Sentencia de 4 de octubre de 2007, Rampion y Godard, C-429/05, Rec. p. I-8017.

Sentencia de 10 de abril de 2008, Hamilton, C-412/06, Rec. p. I-2383.

Sentencia de 14 de mayo de 2009, Ilsinger, C-180/06, Rec. p. I-3961.

Sentencia de 4 de junio de 2009, Pannon GSM, C-243/08, Rec. p. I-4713.

Sentencia de 6 de octubre de 2009, Asturcom Telecomunicaciones, C-40/08, Rec. p. I-9579.

Sentencia de 17 de diciembre de 2009, Martín Martín, C-227/08, Rec. p. I-0000.

Sentencia de 15 de abril de 2010, E. Friz, C-215/08, Rec. p. I-0000.

Sentencia de 3 de junio de 2010, Caja de Ahorros y Monte de Piedad de Madrid, C-484/08, p. I-0000.

Sentencia de 9 de noviembre de 2010, VB Pénzügyi Lízing, C-137/08, Rec. p. I-0000.

Sentencia de 7 de diciembre de 2010, Pammer y Hotel Alpenhof, C-585/08 y C-144/09, Rec. p. I-0000.

\section{Jurisprudencia seleccionada del Tribunal de Justicia en relación con la aplicación de la Carta}

Auto del 6 de octubre de 2005, Vajnai, C-328/04, Rec. p. I-8577.

Sentencia de 27 de junio de 2006, Parlamento/Consejo, C-540/03, Rec. p. I-5769.

Sentencia de 13 de marzo de 2007, Unibet, C-432/05, Rec. p. I-2271.

Sentencia de 14 de febrero de 2008, Varec, C-450/06, Rec. p. I-00581.

Sentencia de 23 de diciembre de 2009, Deticek, C-403/09 PPU, Rec. p. I-0000. Sentencia de 5 de octubre de 2010, McB, C-400/10 PPU, Rec. p. I-0000.

Sentencia de 9 de noviembre de 2010, Volker und Markus Schecke y Eifert, C-92/09 y C-93/09, Rec. p. I-0000. 


\section{Conclusiones de los Abogados Generales citadas en el texto}

Conclusiones presentadas por el Abogado General Poiares Maduro el 9 de septiembre de 2008 en el asunto Elgafaji (Sentencia de 17 de febrero de 2009, C-465/07, Rec. p. I-00921).

Conclusiones presentadas por la Abogada General Trstenjak el 11 de septiembre de 2008 en el asunto Gorostiaga Atxalandabaso/Parlamento (Sentencia de 19 de febrero de 2009, C-308/07 O, Rec. p. I-01059).

Conclusiones presentadas por el Abogado General Mengozzi el 21 de enero de 2009 en el asunto Mono Car Styling (Sentencia de 16 de julio de 2009, C-12/08, Rec. p. 1-06653).

Conclusiones presentadas por la Abogada General Kokott el 22 de enero de 2009 en el asunto Mellor (Sentencia de 30 de abril de 2009, C-75/08, Rec. p. I-03799).

Conclusiones presentadas por la Abogada General Trstenjak el 7 de mayo de 2009 en el asunto Martín Martín (Sentencia de 17 de diciembre de 2009, C-227/08, Rec. p. I-0000). 